\title{
Creation of prototype 3D models using RAPID PROTOTYPING
}

\author{
Jozef Harušinec ${ }^{1, *}$, Andrej Suchánek ${ }^{1}$, and Mária Loulová ${ }^{1}$ \\ ${ }^{1}$ University of Žilina, Faculty of Mechanical Engineering, Department of Transport and Handling \\ Machines, Univerzitná 8215/1, 01026 Žilina, Slovak Republic
}

\begin{abstract}
The article deals with creating 3D models using RAPID PROTOTYPING technology. At present, we are witnessing the integration of new technologies into ordinary life. A good example is the use of FDM (fused deposition modeling) technology that primarily uses thermoplastics to create $3 \mathrm{D}$ models. A few years ago, the use of rapid prototyping technology was a prerogative of companies, research institutes and a narrow group of universities. Technologies such as FDM and STL (Stereolithography) have become affordable in the past few years for smaller businesses and individuals. The specific segment is the replicating rapid prototype RepRap (replicating rapid prototype), the extended version of which is the Prusa i3 printer.
\end{abstract}

Keywords: rapid prototyping, FDM, prototype

\section{Introduction}

However, the development process was limited when converting thoughts stored on a PC disk to a real and tangible body that could be used as a model for a form or as a functional component. Despite the development of numerically controlled machine tools, which were only a digitized version of conventional machine tools, for more complicated components, it took a few days or weeks for the final piece to carry out demanding tests. The change took place after the method of chip-machining was replaced by the material layers method in use for the rapid production of prototype components. The material layers method created the model by laying one layer on the other, and thus the accuracy and time requirements were dependent on the thickness of the layer (Fig. 1).

The first method used was stereolithography (SLA - Stereolitography). From it, the next generations of prototyping methods on 3D printers came out [1-4]. The STL format (Stereolithography), which is currently supported by all CAD programs used in the engineering practice and many commercial and non-commercial modeling software, has been defined as the uniform format for model processing. The primary material used was resin cured by laser beam [5]. Laminated paper or film treated with adhesive was used later which, after application and curing, trimmed with the laser to the desired shape. Other materials that

\footnotetext{
*Corresponding author: jozef.harusinec@ffstroj.uniza.sk

Reviewers: Maciej Berdychowski, Piotr Krawiec
} 
are used are thermoplastic, metal, metallic powders, rock powders and others, depending on the layering process used.

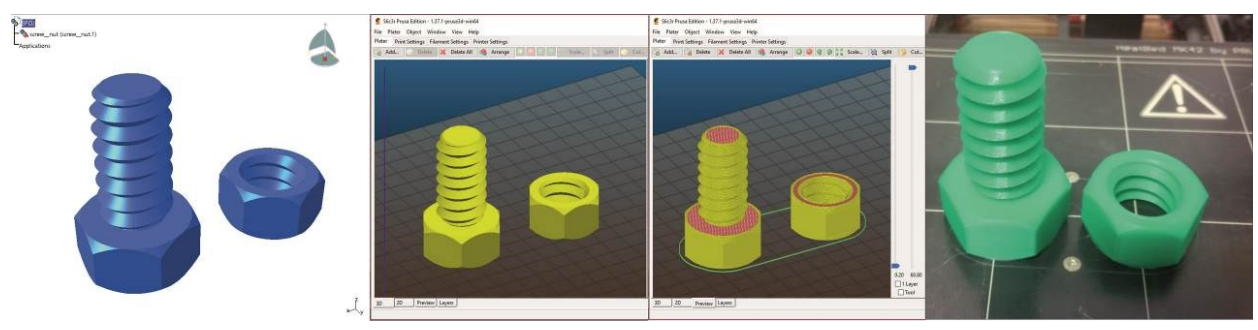

Fig. 1. Process how to create a printed model from a CAD

In industrial practice, SLS is the most widely used technology, because it produces models in a wide range of materials that are solid, and the material is consumed without residue. The disadvantage is the high price and large dimensions of the device. Consumption costs per kilogram of material are relatively high. But this is not decisive in a company, where strength and efficiency of material use are the key factors. A completely different approach is for the person, who wants to use the $3 \mathrm{D}$ printer for private purposes. Such a person requires a low purchase price, low energy demands, high reliability and low cost of consumable material. These parameters meet very well the FDM technology (Fused Deposition Modeling) $[1,6,7]$, where the layers are formed by extruding the thermoplastic through the nozzle and its subsequent cooling. This creates the whole model. The models created by this method are relatively solid. The disadvantage is that at the boundary of the layers the strength of the model is reduced due to the less perfect bonding. This can lead to fractures due to inappropriate design or excessive cyclic loading.

The following conditions were considered when choosing the printer:

- printing space,

- the cost of consumable material,

- construction resistance,

- improvement possibilities.

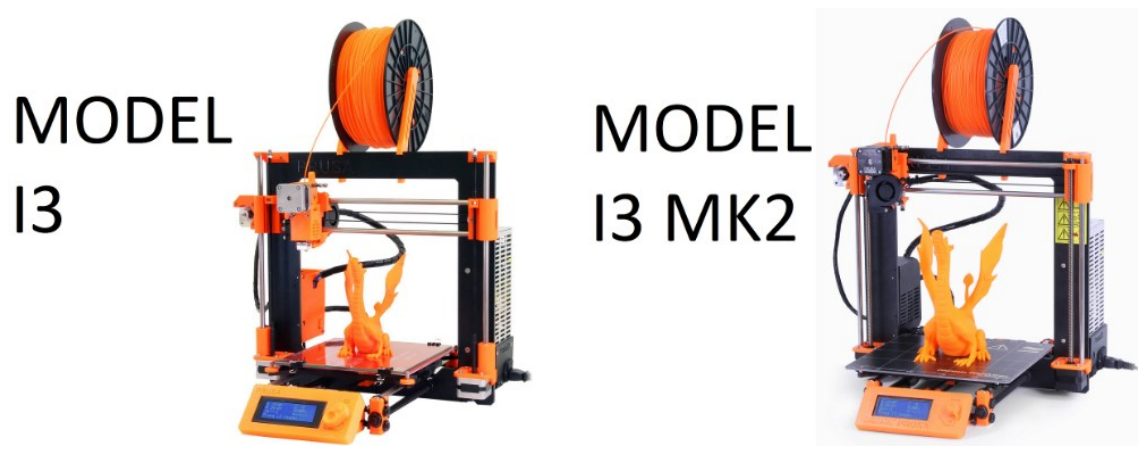

Fig. 2. 3D printer Prusa i3 and Prusa i3

This has brought us to the RepRap (replicating rapid prototyper) [2] project, where the printer and its service software are licensed under the GPL. This ensures that the product can be edited and redistributed or sold, but its specifications need to be published. This in practice means that it is possible to create spare parts on the printer or, based on experience, to modify the geometry of the part and then use it in the device. Such a device is also a Prusa i3 [1] printer (Fig. 2) where 3 types of parts are used: printed from ABS (these parts can replicate the printer), standardized (leads, bearings, screws) and electronic (control circuits, motors, switches). Such a device can be used in the teaching process, but also in the field of promotion 
and testing conducted within the department. Nowadays three pieces of printer Prussia i3 MK2 and one piece of Prusa i3 printer are at the Department of Transport and Handling Technology.

\section{Use of 3D printing in KDMT conditions}

As stated above, printers are used to print objects that help promote the various events organized by the Department and print models of devices that are installed in KDMT laboratories and are not universally accessible to students. On Fig. 3 is displayed a functional model of the RAILBCOT test bench in scale 1:10 [8]. With this model, it is possible to practically demonstrate the features of the test device and also give an idea of the location of individual measuring nodes. This model was presented at the display stand of University of Žilina at the 24th International Engineering Fair in Nitra and participated in the competition organized by the fair in which the mod-el was awarded the "Fair Prize". Also included are promotional materials, including various keychains and plaques, which create positive awareness of the department in both future and current students. The models are made of PLA (polylactic acid), which is a thermoplastic made on a starch base. It is relatively rigid and thermally stable up to $80^{\circ} \mathrm{C}$. It is soluble in acetone. For more stressed parts that have to withstand temperatures higher than $80^{\circ} \mathrm{C}$, ABS (acryloni-trile butadiene styrene) is used. It is a plastic made of petroleum which is also acetone-soluble like PLA.

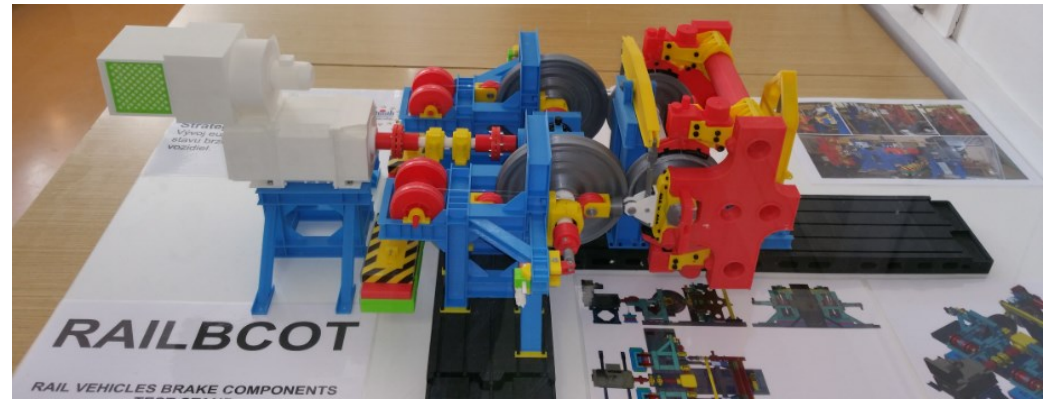

Fig. 3. 3D Model of RAILBCOT Test Stand on a scale of 1:10

The second significant use of the device at the department is the use of equipment as a prototype device for re-search projects realized at the department. As an example, we have created an adapter for the DTA-10G8 surface sensor attachment (Fig. 4). The original solution was developed by KDMT technicians according to the drawing documentation [9-12]. Adapter parts are not enormously mechanically stressed and therefore plastic has been chosen.

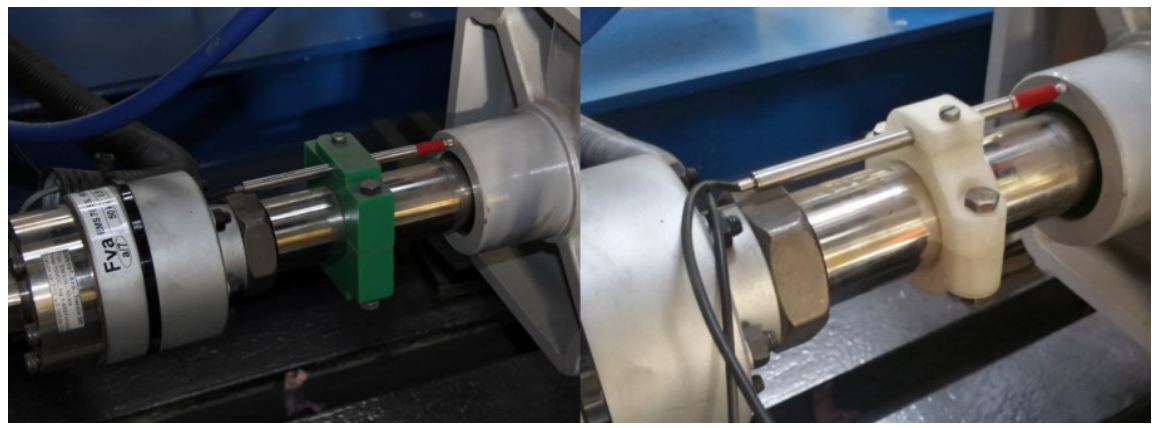

Fig. 4. Design of the position sensor adapter: original (left) and new adapter (right) 
Table 1. Time consuming for Adapter Making

\begin{tabular}{|l|c|c|c|}
\hline & $\begin{array}{c}\text { Production in } \\
\text { contractors workshop }\end{array}$ & $\begin{array}{c}\text { Production in } \\
\text { KDMT } \\
\text { workshop }\end{array}$ & 3D print \\
\hline Design & $25 \mathrm{~min}$ & $25 \mathrm{~min}$ & $25 \mathrm{~min}$ \\
\hline Drawing/Model for printing & $15 \mathrm{~min}$ & $15 \mathrm{~min}$ & $10 \mathrm{~min}$ \\
\hline Production & 7 days & 3 days & $4 \mathrm{hr} 40 \mathrm{~min}$ \\
\hline Delivery & $1 \mathrm{day}$ & 0 day & $0 \mathrm{day}$ \\
\hline Time consumption & $192.67 \mathrm{hr}$ & $72.67 \mathrm{hr}$ & $52.5 \mathrm{hr}$ \\
\hline Mass of component & $0.143 \mathrm{~kg}$ & $0.143 \mathrm{~kg}$ & $0.043 \mathrm{~kg}$ \\
\hline
\end{tabular}

An alternative to own production was ordering the part from an outside supplier. For production in our own direction, the geometry had to be adjusted and relatively simplified so that parts can be manufactured with the workshop equipment. In Fig. 4 on the right is the adapter created on the $3 \mathrm{D}$ printer. In Table 1 is the time consumption as needed for the manufacture of the position sensor adapter.

At first glance, it is clear that the model looks different. This is due to the fact that $3 \mathrm{D}$ print is not limited by conventional technology. This means that the designer can better optimize the design or optimize such product based on feed-back from using the device. In Fig. 5 is a model created in CATIA. Compared to Fig. 4, here can be better seen the fact that the new model is smaller in volume and therefore lighter. Another saving on weight (Table 1) is given by the fact that the interior of the adapter is made up of three layers which form the shell and the internal volume is $20 \%$ and the remaining $80 \%$ is air (Fig. 6). This ratio can be selected from $0 \%$ (without filler) to $100 \%$ (fully-filled).

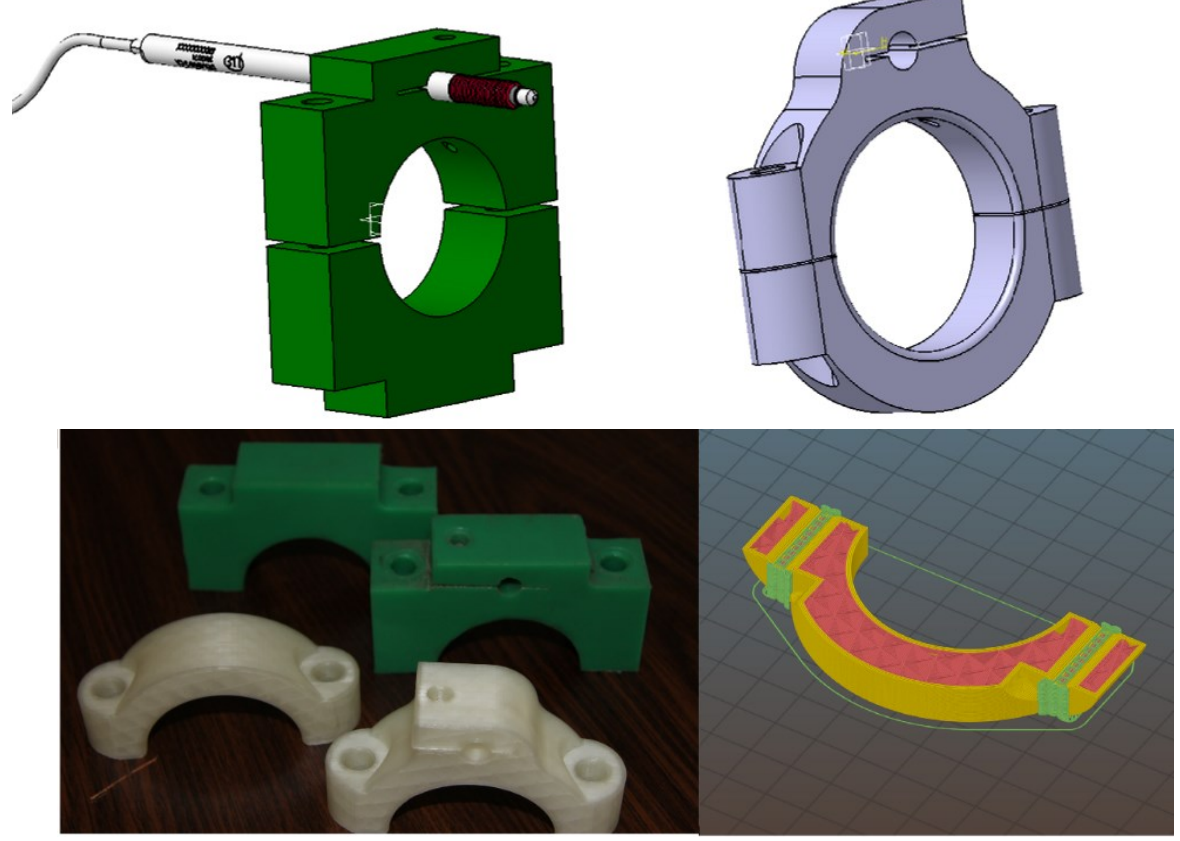

Fig. 5. Comparison of original (green) and innovated adapter (white)

During work on the E3 KOLKA project (Fig. 6) it was necessary to create components whose production would be disproportionately high when using aluminum chip machining parts. That's why we created plastic parts made of ABS and PTGE materials on a 3D printer. Fig. 7 shows the use of individual materials on the guide part. 


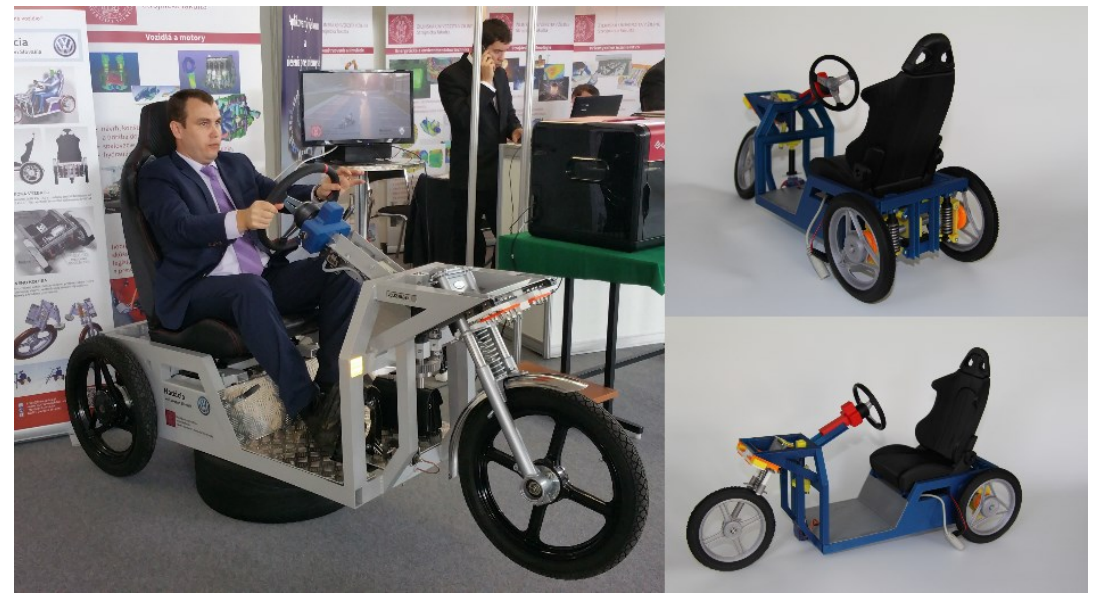

Fig. 6. Three-wheel vehicle E3KOLKA, real vehicle (left) 3D printed model (right)

This has ensured the functionality of sufficient stiffness and inexpensive way to optimize the device as needed. The infill density was set at 80 percent. The model thus created behaved almost like a full body part, and the printing time of the entire construction was 38 hours on two printers. ABS was used, which is strong, hard and PETG, which is strong and more elastic and softer than ABS. PETG is more resistant to fatigue fracture.

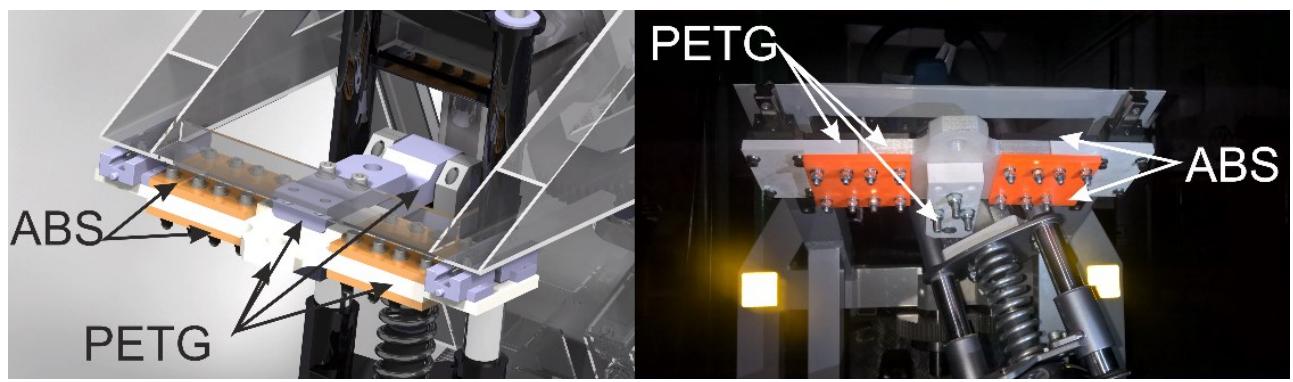

Fig. 7. Driving part of the steering mechanism

Preferably, 3D printing at KDMT department is used on less loaded components. In case of a component that is more stressed, the issue is solved in the literature for full-printed models. The problem occurs when the fill is below $80 \%$, where the material properties change according to the size of the component and are also dependent on the direction of printing. For this reason, we have created a set of samples that have different numbers of outer layers and different fill types at a density of $15 \%$.

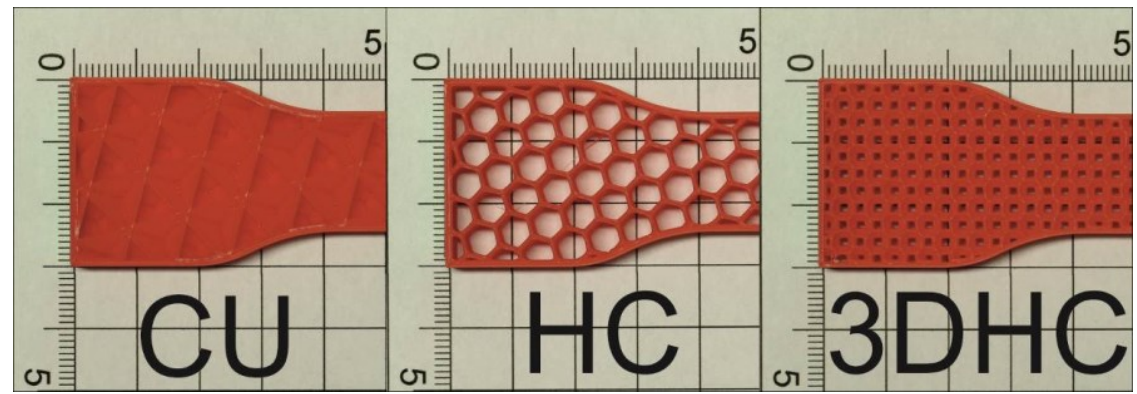

Fig. 8. Samples infill 
We have created samples for ABS and PLA materials. At present, PET samples (PETG) are still in production, and tests will be completed upon completion of the set. Fig. 8 shows the used CU-CUBIC, HC-HONEYCOMB and 3DHC-3D HONEYCOMB (a structure of interconnected tetrahedrons) fillers. We plan to use the results obtained from these experiments to create a more accurate material model and to measure the degree of bonding of shell and core layers at a low fill level.

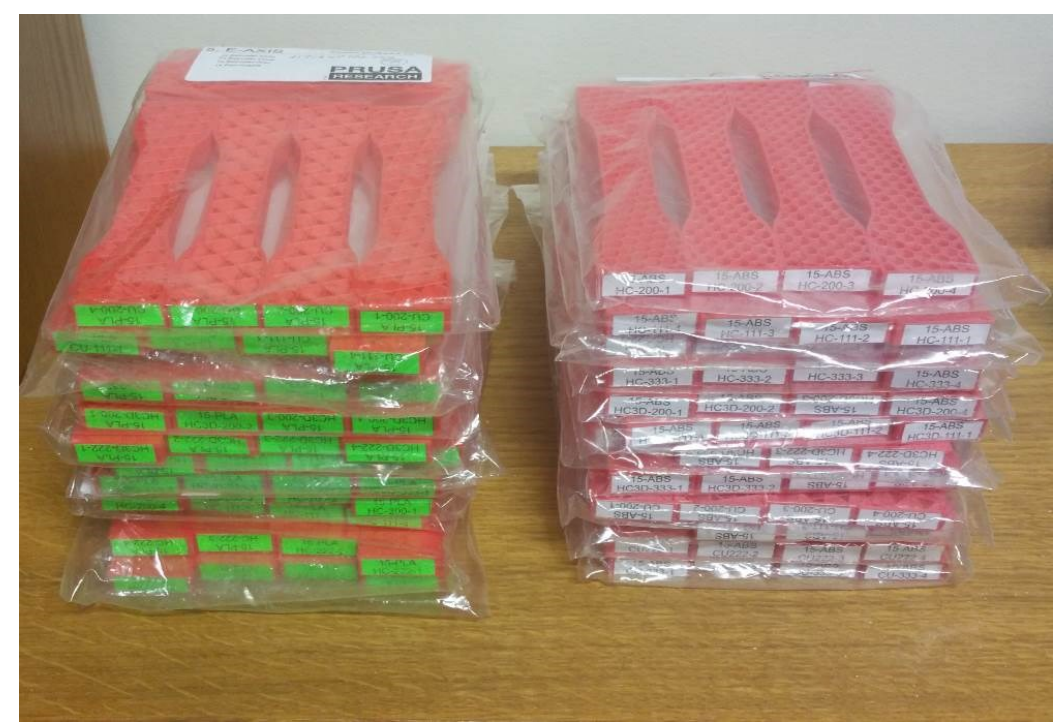

Fig. 9. Samples for tensile tests

Up to now, 1200 samples have been produced (Fig. 9) (60 PLA a $60 \mathrm{ABS}$ ), $\mathrm{Cu}-20 \mathrm{pcs}$, $\mathrm{HC}-20 \mathrm{pcs}, 3 \mathrm{DHC}-20 \mathrm{pcs}, 1-2$ perimeters around core of sample and 0-3 perimeters on top and bottom. Sample labeling CU 200 (Fig. 9):

- $\mathrm{Cu}$ - cubic infill,

- 2 - two perimeters around sample,

- 0 - zero perimeters on the top of sample,

- 0 - zero perimeters on the bottom of sample,

The following set of 5 pieces was created $(200,111,222,333)$.

The test defined in this way should provide information on the influence of the number of perimeters on the overall stiffness of the component.

\section{Adjusting print conditions}

During the production of ABS samples, initially there was a malfunction. When the print height reached $2.5 \mathrm{~mm}$, the base tore itself off from the printing plate on one side, and as the printing continued, faulty pieces as shown in Fig. 10 were produced as a result. A slight improvement has been made when the plate temperature was increased from 100 to $106^{\circ} \mathrm{C}$, but the peeling continued.

These errors occurred mainly in the morning at the first press when the room temperature was around $20^{\circ} \mathrm{C}$. During the day the temperature rose to 30 to $32^{\circ} \mathrm{C}$. From these results we concluded that for better quality printing, it is necessary to increase the ambient temperature or to reduce the temperature change gradient over the print plate. As an insulating barrier we used a protective cover made of Plexiglas (Fig. 11). 


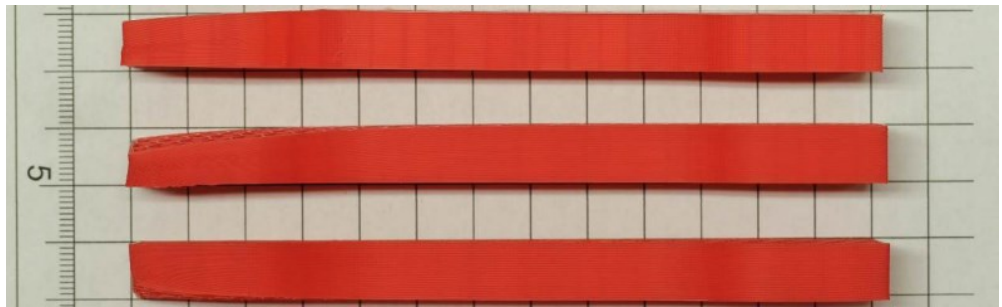

Fig. 10. Errors on samples printed from ABS

The dimensions of this package were $61.5 \mathrm{~cm}$ for $67 \mathrm{~cm}$ for $56 \mathrm{~cm}$ and it was originally produced as a printer protection when displayed on various promotional events attended by the department to prevent injury. After application, print failure has almost disappeared and power consumption has fallen by $35 \%$ compared to open-space printing. After this discovery, FLUKE Ti 400 thermometer was used to measure the temperature during printing and heating of the printing plate.
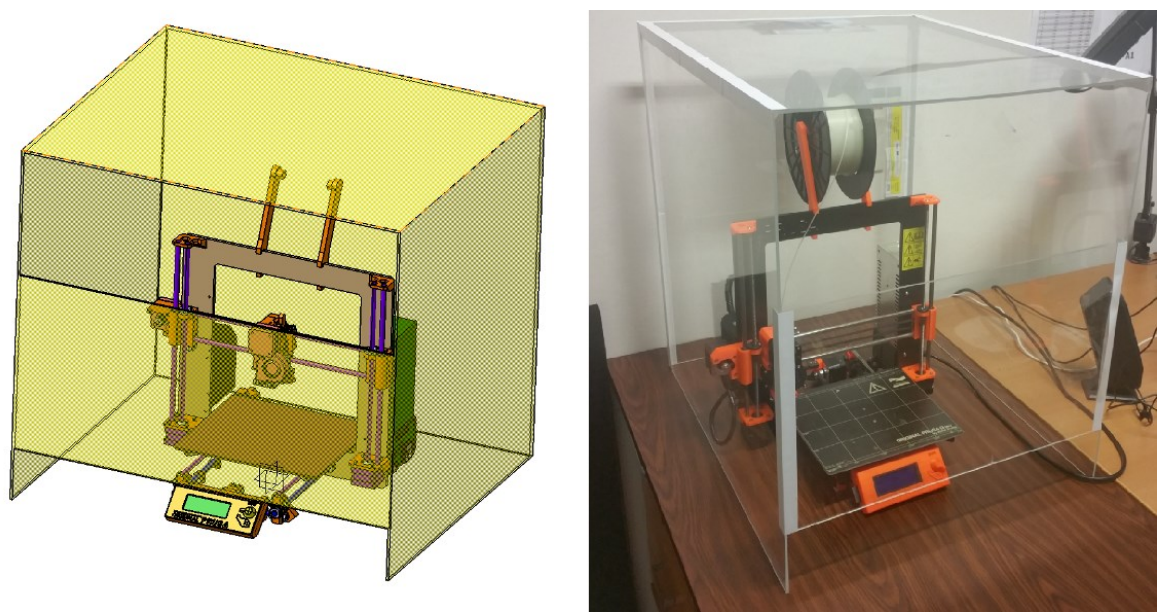

Fig. 11. Protective box made of plexiglass, model (left) prototype (right)

As can be seen from Fig. 12 on the left, when the temperature is set to $106^{\circ} \mathrm{C}$, the deviation in the center of the plate is visible, but the rest of the plate is heated evenly. The right side of Fig. 12 shows a decrease in temperature during printing of higher layers $(3 \mathrm{~mm}$ from the plate when the plate is heated to $55^{\circ} \mathrm{C}$ ).
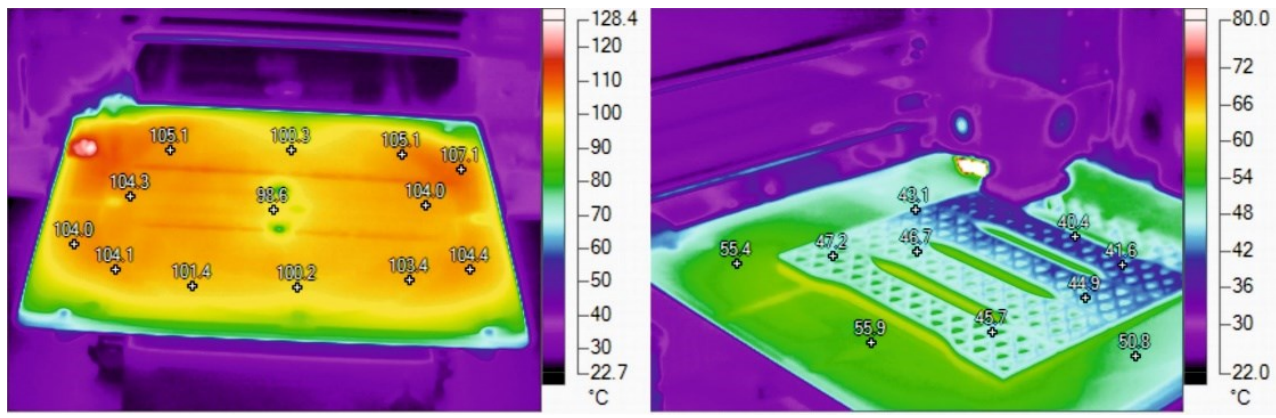

Fig. 12. Temperature distribution on the plate (left) and during print (right) 
Following these findings, we decided to perform an experiment in which we placed a set of K-type thermocouples on the plate, sequentially spaced from the plate at $10 \mathrm{~mm}$ spacing (Fig. 13).

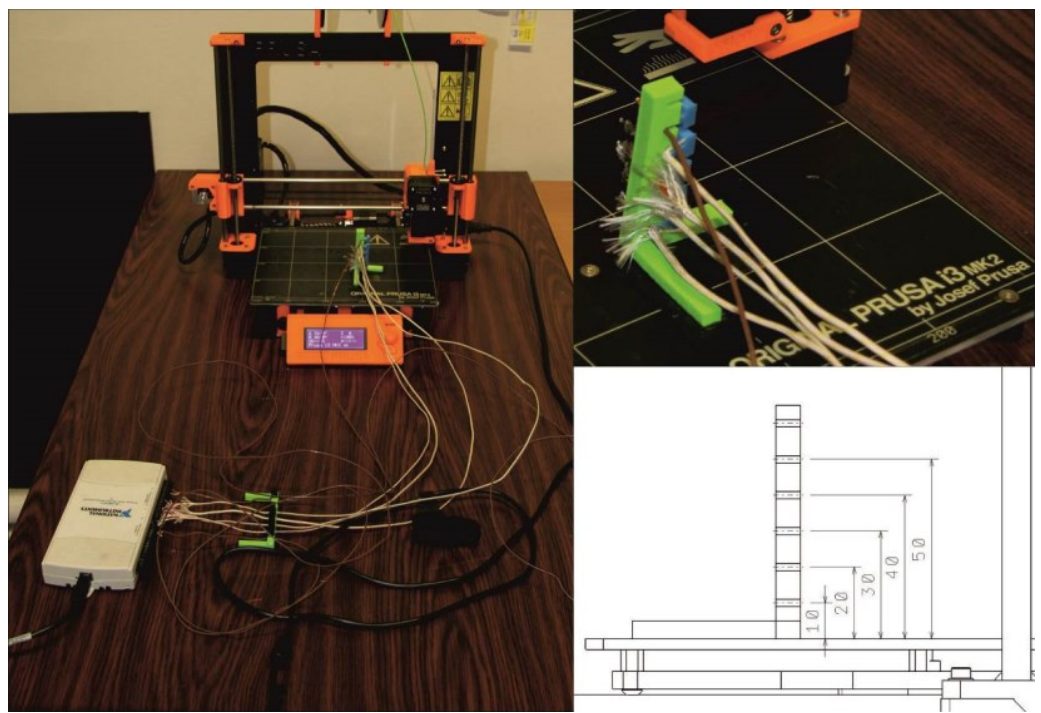

Fig. 13. Temperature measurement on the printer board

The experiment was carried out for 30 minutes after the target temperature of the plate reached $60^{\circ} \mathrm{C}$. At that time, the temperature recording started. This was shot at a height of 10 to $50 \mathrm{~mm}$ above the print plate. This was done without a protective box and a with a protective box. The results are presented in Fig. 14 and Fig. 15. It is clear from the results that by insulating the print space, it is possible to reduce the temperature change over the print plate by about $5^{\circ} \mathrm{C}$ and also to reduce the power consumption and the most important aspect of this change is to improve the quality of the ABS prints. The next step will be to create an ergonomically suitable package that would allow for even better use of energy than the current temporary solution.
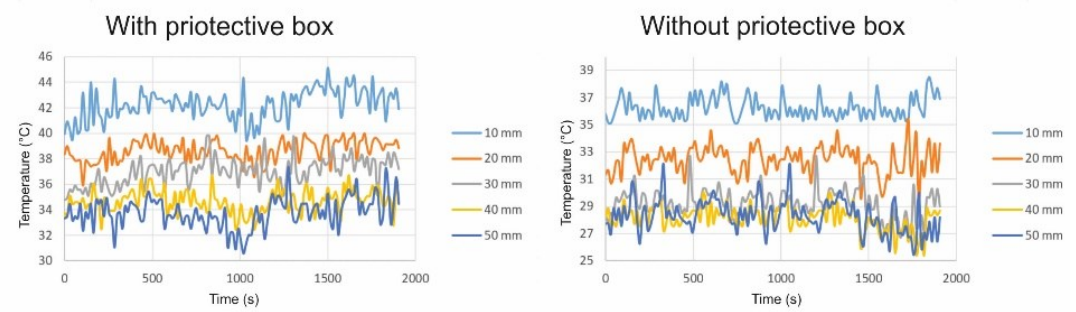

Fig. 14. Distribution of temperature values above the print plate
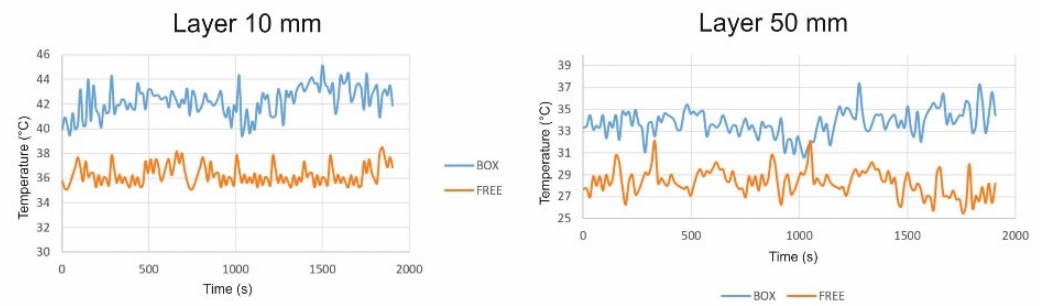

Fig. 15. Temperature difference above the print plate 


\section{Strength of 3dprinted objects}

Based on the results of the tensile test specimens described in Chapter 2, we want to create a FEM model of the material whit infill to better describe the printed parts that have a infill density of less than 80 percent. These are products where the size of the component needs to be dimensioned enough while maintaining a low weight.

In the past, we have found that the bulk of the mechanical properties research focuses on prints made with full infill models. In Fig. 16 shows the fiber layout after printing and the result of the tensile test.
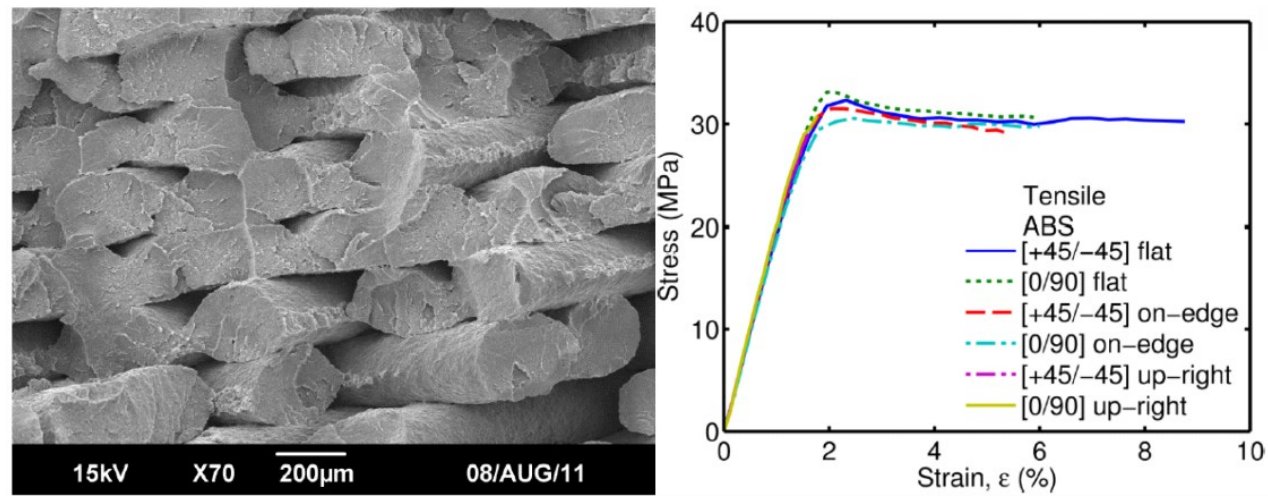

Fig. 16. Deposition ABS fibers in sample (left), tensile diagram (right) [3]

For design purposes, we are interested in the linear part of tensile diagram, especially the values of the Young's modulus, the Poisson number, and the Yield stress value are important for us $[13,14]$.

The comparative FEM model has therefore been exposed in the ANSYS program to conditions like was created by the test device during the tensile test [15]. The geometry of the model is identical to the geometry of the sample made on the printer. The Fig. 17 shows a geometric model for FEM analysis.
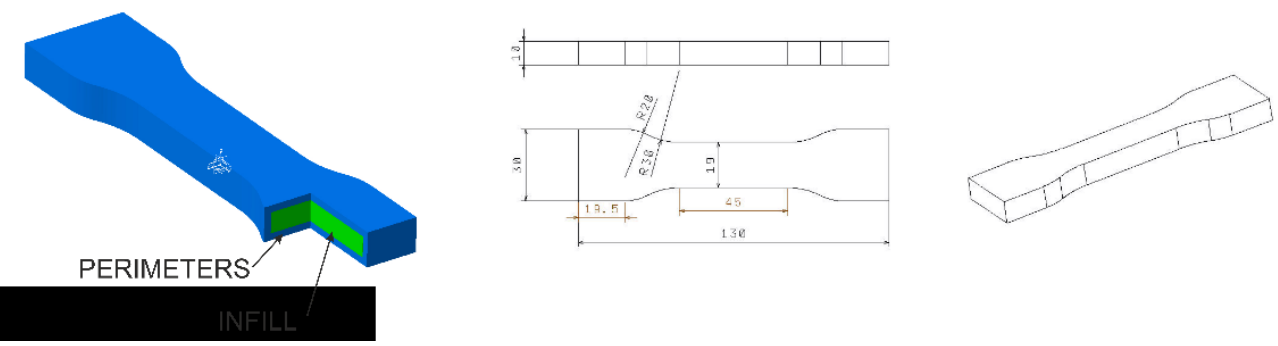

Fig. 17. Material distribution in sample (left), sample dimensions (right)

For the pre-validation, we compared two samples. In the first case, the $100 \%$ infill model and in the second case $0 \%$. Fig. 18 shows both samples (geometry and scales). The mesh was formed by $2 \mathrm{~mm}$ hexahedrons.

Material properties: $E=1.1-2.9 \mathrm{GPa}, \mu=0.42$.

The test device will be a mechanically stretched sample and record the elongation of the sample and the force generated in the sample. Similarly, was defined the displacement of the sample end in the direction of the tensile stress (Fig. 19). After analysis, it was clear that the stress distribution was comparable on both samples. 

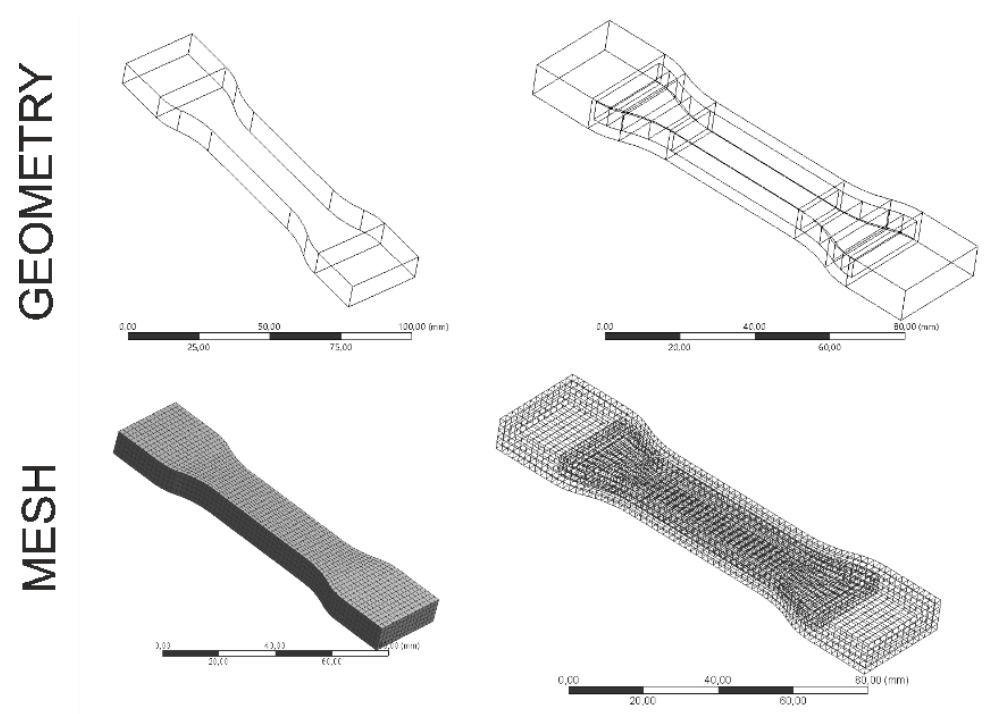

Fig. 18. Geometry and meshed model., sample with full core (left), sample with empty core (right)
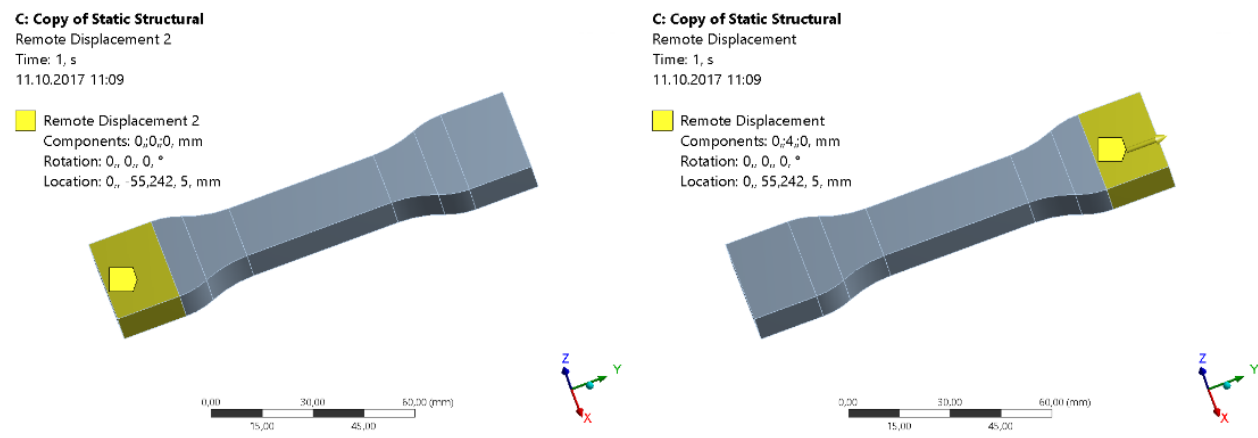

Fig. 19. Boundary condition
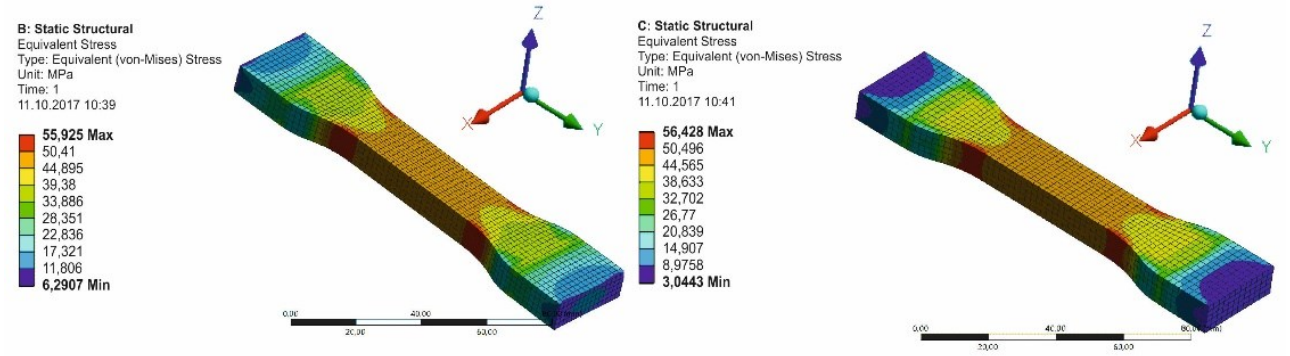

Fig. 20. HMH stress distribution, sample with full core (left), sample with empty core (right)

But the difference is in the force that is needed to produce this displacement. On Fig. 21 shows the stiffness of the sample in the case of a full and empty core. After the tensile tests, it will be possible to tune the sample core material so that the first approach to reality is made. We believe that this model will allow for a more accurate dimensioning of stressed parts. 


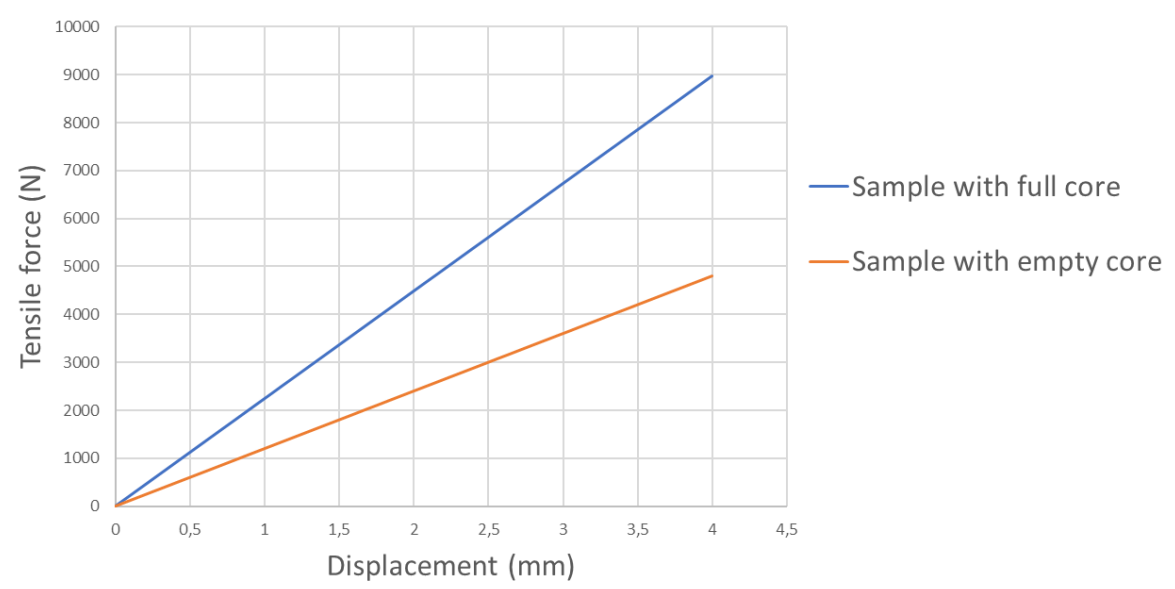

Fig. 21. Stiffness of the sample

\section{Conclusion}

In our article we focused on the possibilities of using the Prusa i3 MK2 printer at the Department of Transport and Handling Technology. It is a use for research and promotion support purposes. As this device is modifiable, the pedagogical activity of the department can also be improved on its basis. The i3 MK2 models were acquired in December 2016, and in the summer semester, a course was developed on the basis of students' interest where the principles of rapid prototyping and work on I3 and I3 MK 2 printers were shown and where they learned about the possibilities of use of these devices and learned the basics of work with this device and especially with the software for model preparation. As this printer is a "jigsaw", it is possible to use it for other projects where the control circuit can be reprogrammed for conditions of use in a crane or other transport or handling device, and in this direction the student will get out of the area where design ends with a virtual 3D model to areas of tangible results.

With this research and development subjects deals other publications too [16-25].

The work was supported by the Cultural and Educational Grant Agency of the Ministry of Education of the Slovak Republic in project No. KEGA 077ŽU-4/2017: Modernization of the Vehicles and engines study program. The work was also supported by the project No. APVV-0842-11: Equivalent railway operation load simulator on the roller rig and VEGA No. 1/0927/15: Research of the use of alternative fuels and hybrid drives on traction vehicles with aim to reduce fuel consumption and air pollutants production.

Research-Educational Centre of Rail Vehicles (VVCKV)

\section{References}

1. www.prusa3d.com, (2018)

2. http://reprap.org/, (2018)

3. J. Cantrell et al., Experimental Characterization of the Mechanical Properties of 3D Printed ABS and Polycarbonate Parts. In: Yoshida S., Lamberti L., Sciammarella C. (eds) Advancement of Optical Methods in Experimental Mechanics, Volume 3. Conference Proceedings of the Society for Experimental Mechanics Series. Springer, Cham. (2017) 
4. J. Dižo, M. Blatnický, B. Skočilasová, Computational modelling of the rail vehicle multibody system including flexible bodies. Communications - Scientific letters of the University of Žilina 17 (3), 31-36 (2015), ISSN 1335-4205

5. T. Lack, J. Gerlici, Modified strip method utilization for wheel/rail contact stress evaluation. 9 $^{\text {th }}$ International Conference on Contact Mechanics and Wear of Rail/Wheel Systems, CM 2012, Chengdu, China, 87-89 (2012).

6. T. Lack, J. Gerlici, Contact area and normal stress determination on railway wheel/rail contact. Communications - Scientific letters of the University of Žilina 7 (2), 38-45 (2005), ISSN 1335-4205

7. T. Lack, J. Gerlici, Wheel/rail contact stress evaluation by means of the modified strip method. Communications - Scientific letters of the University of Žilina, 15 (3), 126-132 (2013), ISSN 1335-4205

8. J. Gerlici, T. Lack, Rail vehicles brake components test bench utilisation. Applied mechanics and materials 486, 379-386 (2014), ISSN 1660-9336

9. M. Blatnický, M. Štauderová, J. Dižo, Numerical analysis of the structure girder for vehicle axle scale calibration. Procedia Engineering 177, 510-515 (2017), ISSN 18777058

10. J. Dižo, S. Steišunas, M. Blatnický, Vibration analysis of a coach with the wheel-flat due to suspension parameters changes. Procedia Engineering 192, 107-112 (2017), ISSN $1877-7058$

11. J. Gerlici, M. Gorbunov, K. Kravchenko, R. Domin, M. Kovtanets, T. Lack, Slipping and skidding occurrence probability decreasing by means of the friction controlling in the wheel-braking pad and wheel-rail contacts. Manufacturing technology 17 (2), 179186 (2017), ISSN 1213-2489

12. T. Lack, J. Gerlici, Wheel/rail tangential contact stress evaluation by means of the modified strip method. Communications - Scientific letters of the University of Žilina 6 (3a), 33-39 (2014), ISSN 1335-4205

13. J. Gerlici, T. Lack, Modified HHT method for vehicle vibration analysis in time domain utilisation. Applied mechanics and materials 486, 396-405 (2014), ISSN 1660-9336

14. M. Blatnický, M. Štauderová, J. Dižo, Numerical analysis of the structure girder for vehicle axle scale calibration. Procedia Engineering 177, 510-515 (2017), ISSN 18777058

15. J. Gerlici, T. Lack, Rail vehicles brake components test bench utilisation. Applied mechanics and materials 486, 379-386 (2014), ISSN 1660-9336

16. P. Baran, M. Brezáni, P. Kukuča, P. Št’astniak, Basic dynamical analysis and comparison of balancing systems of non-conventional piston machine FIK. Procedia Engineering. ISSN 1877-7058. Vol. 192, pp. 34-39 (2017)

17. P. Baran, P. Št’astniak, P. Kukuča, M. Brezáni, Investigation of kinematic parameters of two nonconventional piston machines with wobble board. MATEC Web of conferences. ISSN 2261-236X. Vol. 157 (2018)

18. J. Gerlici, T. Lack, Contact geometry influence on the rail / wheel surface stress distribution. Procedia Engineering 2 (1) 2249-2257 (2010), ISSN 1877-7058

19. J. Gerlici, T. Lack, Contact geometry influence on the rail / wheel surface stress distribution. Procedia Engineering 2 (1), 2249-2257 (2010), ISSN 1877-7058 
20. T. Lack, J. Gerlici, Wheel/rail tangential contact stress evaluation by means of the modified strip method. Communications - Scientific letters of the University of Žilina 6 (3a), 33-39 (2014), ISSN 1335-4205

21. T. Lack, J. Gerlici, A modified strip method to speed up the calculation of normal stress between wheel and rail. Applied mechanics and materials 486, 359-370 (2014), ISSN 1660-9336

22. T. Lack, J. Gerlici, A modified strip method to speed up the tangential stress between wheel and rail calculation. Applied mechanics and materials 486, 371-378 (2014), ISSN 1660-9336

23. L. Smetanka, P. Št'astniak, Analysis of contact stresses of theoretical and worn profile by using computer simulation. Manufacturing Technology 17 (4), 580-585 (2017), ISSN 1213-2489

24. P. Št’astniak, M. Moravčík, P. Baran, L. Smetanka, Computer aided structural analysis of newly developed railway bogie frame. MATEC Web of conferences 157 (2018), ISSN 2261-236X

25. P. Štastniak, Wagon chassis frame design with adaptable loading platform. Manufacturing Technology 15 (5), 935-940 (2015), ISSN 1213-2489 